\title{
Modeling of soil mechanical resistance using intelligent methods
}

\author{
Mehdi Hosseini ${ }^{1}$, Seyed Ali Reza Movahedi Naeini ${ }^{2}$, Amir Ahmad Dehghani ${ }^{3}$, Mojtaba \\ Zeraatpisheh $^{4 *}$
}

${ }^{1}$ Department of Soil Science, Tarbiat Modares University, Tehran, Iran. ${ }^{2}$ Department of Soil Science. Gorgan University of Agricultural Sciences and Natural Resources, Gorgan, Iran. Postal code: 49138-15739. ${ }^{3}$ Department of Water Engineering. Gorgan University of Agricultural Sciences and Natural Resources, Gorgan, Iran. ${ }^{4 a}$ Department of Soil Science, College of Agriculture, Isfahan University of Technology, 84156-83111; Isfahan, Iran. ${ }^{b}$ Key Laboratory of Geospatial Technology for the Middle and Lower Yellow River Regions, College of Environment and Planning, Henan University, Kaifeng, Henan. Province, China. 'Department of Soil Science, Ramin Agriculture and Natural Resources University of Khuzestan, Ahvaz, Iran

*Corresponding author: m.zeraatpishe@alumni.iut.ac.ir

\begin{abstract}
In recent years, novel techniques such as intelligent techniques are being employed for developing predictive models to estimate parameters that are difficult to measure. For instance, determining soil mechanical resistance is difficult, particularly in fine-textured soils and during warm seasons. In this research, we used statistical algorithms, adaptive neuro-fuzzy inference systems (ANFIS), artificial neural networks (ANNs) and fuzzy inference systems (FIS) in order to predict soil mechanical resistance and compared them with traditional statistical models such as multiple regression (MR). To achieve this goal, bulk density, volumetric soil water content (as predictors) and soil mechanical resistance (as target variable) were used at 0-25 cm depth with sample size equals 200. The results showed that intelligent methods are appropriate tools for minimizing the uncertainties in soil engineering projects. The ANFIS model predicted soil mechanical resistance more accurately than the other models with $\mathrm{R}^{2}=0.93$ and $\mathrm{RMSE}=299.41$. Also, the use of intelligent methods not only provided new approaches and methodologies to estimate soil mechanical resistance, but also minimized the potential inconsistency of correlations.
\end{abstract}

Keywords: Farm management, root growth, soil mechanical modeling, soil properties. 


\section{Introduction}

Soil compaction affects on root penetration in the soil system, hydrological processes and crop production (Rodrigo-Comino et al., 2017). Penetrometry is considered as a suitable method to evaluate mechanical resistance to root penetration into the soil (Hosseini et al., 2016). Results obtained from this method represents the force required to drive a metal cone into the soil to simulate plants' roots. Among the soil parameters affecting on soil mechanical resistance, soil water content and bulk density are the most significant ones (Nasri et al., 2015). Soil mechanical resistance is well-correlated with root growth and varies inversely proportional to it. When soil water content decreases, an increase in mechanical resistance occurs, because cohesion within the solid fraction of soil diminishes (Bengough et al., 2001). Thus, when soil mechanical resistance values vary from 1.0 to 3.5 MPa (Nasri et al., 2015), root growth can be restricted or even impeded. Penetration resistance has been observed to be more sensitive than bulk density to detect the effect of tillage management (Hosseini et al., 2016). It can be related to increasing resistance to root growth and decreasing water and nutrient use efficiencies (Hosseini et al., 2014).

Determination of soil mechanical resistance is difficult. Consequently, there is a vital need to develop an easy, accurate and low-cost tool to determine soil properties and improve the soil system management in areas where data is scarce or non-existent (Pulido et al., 2015). For these reasons, intelligent models have also been developed to predict nonexplicit relationships among variables (Cagliari et al., 2011). Intelligent approaches such as adaptive neuro-fuzzy inference systems (ANFIS), artificial neural networks (ANNs), non-linear regression and fuzzy inference system (FIS) are enable to model spatially the complex systems have been recently used (Khaledian et al., 2017) to determine soil parameters. They are also becoming increasingly important in all engineering areas as a result of rapid development of information and computers technology (Khaledian et al., 2017). These methods enable the pattern recognition, classification, speech recognition, design of structures, automatic control, manufacturing process control, and modeling of material behavior (Adam, 2003).

Several studies have recently been conducted to predict soil properties, such as swell potential of clayey soils (Yilmaz and Kaynar, 2011), shearing resistance (Kayadelen, 2009), and soil classes (Zeraatpisheh et al., 2017). According to Movahedi Naeini et al. (2012), soil mechanical resistance measurements could defined irrigation timing better than soil water content, because soil mechanical resistance restricted root growth, water and nutrient uptake in soils. Therefore, in order to accurately predict soil mechanical resistance from soil water contents, recognizing tissue water and stress-mechanical resistance might be useful to the farmers and agronomists.

Although soil compaction is a problem in the north of Iran, such as Golestan province, due to high soil specific surface area (Zeraatpishe and Khormali, 2012; Hosseini et al., 2016), but there is a lack of information about the understanding of soil compaction. In this paper, advanced statistical approaches, ANFIS, ANN, FIS, and MR, were assessed for the prediction of the mechanical resistance that is hard to measure. The main goals of this study were to i) estimate soil mechanical resistance by two basic soil properties, bulk density $\left(f_{b}\right)$ and volumetric soil water content $(\theta \mathrm{v})$, using ANFIS, ANN, FIS and MR models, and ii) compare these models in order to present the optimal one in predicting the mechanical resistance. 


\section{Materials and Methods}

\subsection{Study area and sampling pattern}

This research was carried out in a $3000 \mathrm{~m}^{2}$ study area at the Gorgan University of Agricultural Sciences and Natural Resources' Research Farm $37^{\circ} 45^{\prime} \mathrm{N}, 54^{\circ}$ $30^{\prime} \mathrm{E}$, Grogan, Iran.

The soil textural class was silty clay loam (sand $19.4 \%$, silt $57.5 \%$, clay $23.1 \%$ ) as measured by the hydrometer method (Gee and Bauder, 1986). Soil organic carbon content of $0.7 \%$ measured using a potassium dichromate method (Chapman, 1965). Soil pH value reached 7.9 and was determined in soil extract by $\mathrm{pH}$-electrode (McLean, 1982) and soil bulk density registered $1.59 \mathrm{~g} \mathrm{~cm}^{-3}$.

The conventional tillage consisted of moldboard ploughing followed by one discing. It is a method commonly used by farmers in this region to help break clod aggregate and make a proper seedbed. The double-disc was consisted of two discings followed by one levelling. Primary tillage depths for moldboard and rototiller were $20-25$ and $8-10 \mathrm{~cm}$, respectively. All disc operations were performed to a depth of $8-10 \mathrm{~cm}$.

In this research 200 undisturbed soil samples were taken from $0-25 \mathrm{~cm}$ depth by stainless steel cylinders $\left(2.65 \mathrm{~cm}\right.$ radius and $4.45 \mathrm{~cm}$ height, $\left.98 \mathrm{~cm}^{3}\right)$ for measuring bulk density and volumetric soil water content. Soil mechanical resistance was determined in situ by a cone penetrometer under the soil water content from the field (Hosseini et al., 2016). Bulk density was measured by method by Brasher et al. (1966) and volumetric soil water content was determined by the method developed by Black (1965). The data were divided into two parts, calibration data subset (160 samples) and validation data subset (40 samples). Data subsets were used for determining the performance of four simulation methods: adaptive neuro-fuzzy inference system (ANFIS), artificial neural networks (ANNs), fuzzy inference system (FIS) and multiple regression (MR). Estimation of soil mechanical resistance using a multiple regression was initially carried out using statistical analysis system software (SAS, version 8). And Matlab software (version 6) was used to run the intelligent models.

\subsection{Modeling approaches}

\subsubsection{Fuzzy inference system (FIS)}

The basic principle of fuzzy modeling was stated by Zadeh )1973( as follows: the use of linguistic variables in place of or in addition to numerical variables; the characterization of simple relations between variables by the conditional fuzzy statement; and the characterization of complex relations by fuzzy algorithms. Production rules are generally expressed in the pattern of IF-THEN, which consists of a condition (IF-part) and conclusion (THEN-part). Thus, they are also called fuzzy IF-THEN rules. The IF-part can consist of more than one precognition linked together by linguistic conjunctions such as AND OR.

Figure (1a) shows a typical structure of a fuzzy inference system. The computation of a fuzzy inference system (FIS) generally consists of three major steps: (1) fuzzification; (2) inference (or reasoning); and (3) defuzzification. Fuzzification is the first step in the computation of a fuzzy system and it must be performed for each input variable. It is a process of mapping the crisp numbers into the fuzzy domain using the membership functions of linguistic variables to compute each term's degree of validity at specific operation point of the process. The result of fuzzification is used as input for the fuzzy inference engine. 

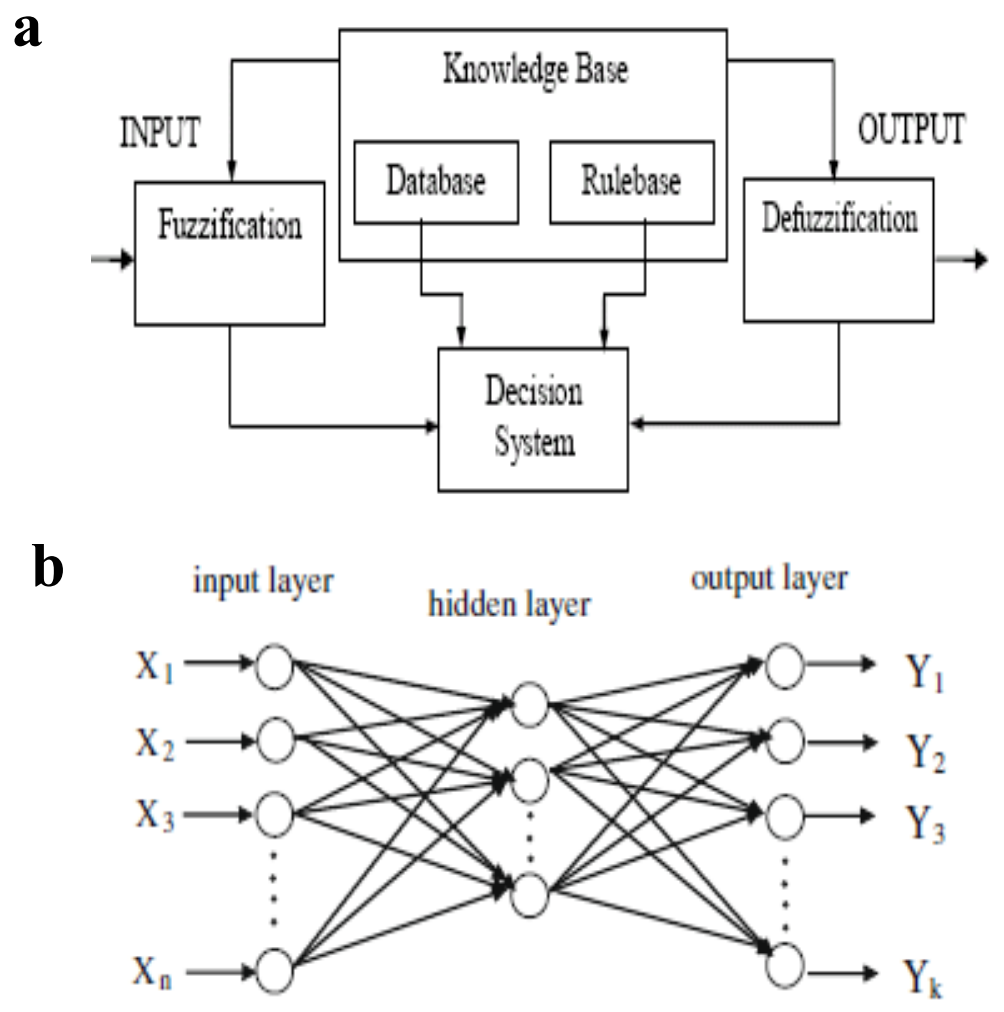

Figure 1. a) Fuzzy inference system structure and b) a multilayer ANN configuration.

\subsubsection{Artificial neural network (ANNs)}

The main purpose of ANN of which working principle is inspired by the way biological nervous systems, such as the human brain, process information which is similar to that of polynomial regression (Das et al., 2014). However, its methodology for the mathematical process is different from the classical regression analyses. In order to obtain the optimal multidimensional surface for the prediction of a dependent variable, any composite functions are fitted to the data presented to the
ANN model modifying the parameters of the composite functions by performing an iterative training process (Stegemann and Buenfeld, 2002). The most widely-used training algorithm is the feedforward, multilayer perceptrons trained by backpropagation algorithms based on gradient descent method (FFBP) (Chang and Islam, 2000). FFBP works based on supervised rule by sending inputs forward and then propagating errors backward. A feed-forward network configuration with two layers (one hidden layer and output layer) is plotted in Figure (1b). 
In this research, the network was designed with 10 nodes in the input layer (bulk density and volumetric soil water content) and 1 node in output layer and the best transmission function was Tansig for the structure of the neural network. For training neural network, Matlab software (version 6) was utilized. Training processes include weight changes between various layers until the minimum difference is obtained between real and predicted data. Finally, the best network structure was selected based on minimum RMSE and maximum $\mathrm{R}^{2}$ (Liu et al., 2001). The accuracy of the models evaluated based on the test dataset.

\subsubsection{Adaptive neuro-fuzzy inference system (ANFIS)}

The other soft computing method used in soil engineering is the neuro-fuzzy modeling (Yilmaz and Yuksek, 2009). A neuro-fuzzy system is, in fact, a neural network that is functionally equivalent to the fuzzy inference model. It can be trained to develop IF-THEN fuzzy rules and determine membership functions for input and output variables of the system (Negnevitsky, 2002). One of the neuro-fuzzy inference systems is the adaptive neuro-fuzzy inference system (ANFIS). The Sugeno model was proposed for a systematic approach to generating fuzzy rules from a given input-output dataset (Negnevitsky, 2002). Jang (1993) proposed a new fuzzy logic model called ANFIS, which employs some properties of artificial neural network (ANN) such as learning and parallelism. Fuzzy rules and membership functions are also generated adaptively by neural training process. For that purposes, ANFIS employs two methods called grid partitioning and subtractive clustering (Demuth and Beale, 2001). A linear function is named as firstorder Sugeno type fuzzy inference system and constant function is named as zero-order Sugeno type fuzzy inference system. A typical two if-then rules in first-order Sugeno type is given at the following form:

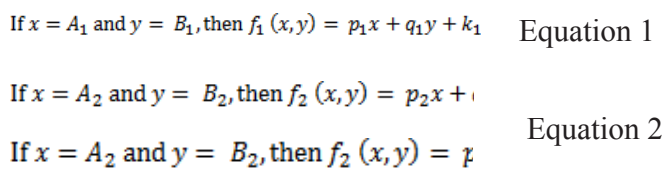

Where $\mathrm{x}$ (or $\mathrm{y}$ ) is the input node $\mathrm{i}, \mathrm{p}, \mathrm{q}$, and $\mathrm{k}$ are the consequence parameters obtained from the training, $\mathrm{A}$ and $\mathrm{B}$ are labels of the fuzzy set defined suitable membership function. The membership function is updated by back-propagation learning algorithm or a hybrid learning algorithm which is described in detail in Demuth and Beale (2001). The basic structure of an ANFIS model is depicted by Padmini et al. (2008).

\subsection{Accuracy Indicators}

The accuracy of models evaluated using mean error(ME), value account for(VAF), root mean square error(RMSE), $\mathrm{R}^{2}$ and mean absolute percentage error(MAPE).

$\mathrm{ME}=\frac{\sum[\mathrm{P}(\mathrm{si})-\mathrm{M}(\mathrm{si})]}{\mathrm{n}} \quad$ Equation 3

$\mathrm{VAF}=\left[1-\frac{\operatorname{Var}(\mathrm{P}(\mathrm{si})-\mathrm{M}(\mathrm{si})}{\operatorname{Var}(\mathrm{M}(\mathrm{si})}\right] \times 100 \quad$ Equation 4

RMSE $=\sqrt[2]{\left\{\frac{\sum[\mathrm{p}(\mathrm{si})-\mathrm{M}(\mathrm{si})]^{2}}{\mathrm{n}}\right\}}$

RMSE $=\sqrt[2]{\left\{\frac{\sum[\mathrm{p}(\mathrm{si})-\mathrm{M}(\mathrm{si})]^{2}}{\mathrm{n}}\right\}} \quad$ Equation 5

$R^{2}=1-\frac{\sum_{i=1}^{n}[M(s i)-P(s i)]^{2}}{\sum_{i=1}^{n}[M(s i)-A(s i)]^{2}} \quad$ Equation 6

where P (si), M (si) and A (si) are amounts of predicted, measured and average soil mechanical resistance and $n$ is sampling point number. Mean error (ME) index (Equation 2) expresses the degree of nondiagonal estimation that should be near zero. VAF 
(Equation 4) and RMSE (Equation 5) indices were calculated to control the performance of the prediction capacity of predictive model developed in the study as employed by Yilmaz and Yuksek (2009). If the VAF is 100 and RMSE is 0 , then the model will be excellent. And, also, $\mathrm{R}^{2}$ (Equation 6), is one of the statistics used in intelligent methods articles. Mean absolute percentage error (MAPE) which is a measure of accuracy in a fitted series value in statistics was also used for comparison of the prediction performances of the models. MAPE usually expresses accuracy as a percentage (Equation 7).

MAPE $=\frac{\sum_{i}^{N}\left|\frac{A i-P i}{A i}\right|}{N} \times 100$
Where $A i$ is the actual value and $P i$ is the predicted value. The obtained values of ME, VAF, RMSE, and MAPE may indicate prediction performances.

\section{Results}

3.1. Bulk density, volumetric soil water content, and mechanical resistance

Results of descriptive statistics of soil mechanical resistance in the studied area are presented in Table 1. Mechanical resistance showed a CV of $53.1 \%$. Normalization test illustrated that soil mechanical resistance registered a normal distribution. Skew varied between -1.28 to 0.12 . Soil water content ranged from 0.06 to $0.79 \mathrm{~cm}^{3}$ $\mathrm{cm}^{-3}$, with a $\mathrm{CV}$ of $53.8 \%$ and bulk density ranged from 0.94 to $1.71 \mathrm{~g} \mathrm{~cm}^{-3}$, with a $\mathrm{CV}$ of $10 \%$.

Table 1. Descriptive statistics of soil parameters in the study farm.

\begin{tabular}{ccccccc}
\hline Soil parameters & Minimum & Maximum & Mean & CV\% & Skew & Kurtosis \\
\hline Soil mechanical resistance (MPa) & 329.66 & 4907.58 & 2384.52 & 53.1 & 0.12 & -1.28 \\
Soil water content $\left(\mathrm{cm}^{3} \mathrm{~cm}^{-3}\right)$ & 0.06 & 0.79 & 0.31 & 53.8 & 0.54 & -0.49 \\
Bulk density $\left(\mathrm{g} \mathrm{cm}^{-3}\right)$ & 0.94 & 1.71 & 1.44 & 10 & -0.54 & -0.14 \\
\hline
\end{tabular}

Coefficient of variation (CV), Coefficient of skewness (Skew)

\subsection{Comparison of ANFIS, ANN, FIS and MR models}

Multiple regression model predicts soil mechanical resistance using soil bulk density and volumetric soil water content:

$$
\begin{aligned}
& m r=3116.515 f_{b}-4128.988 \theta_{V}-817.129 \\
& m r=3116.515 f_{b}-4128.988 \theta_{V}-817.129 \text { Equation } 8
\end{aligned}
$$


where $m r, f_{b}$ and $\theta_{\mathrm{v}}$ are mechanical resistance (MPa), dry bulk density $\left(\frac{\mathrm{gr}}{\mathrm{cm}^{3}}\right)$ and volumetric soil water content $\left(\frac{\mathrm{cm}^{\mathrm{s}}}{\mathrm{cm}^{\mathrm{s}}}\right)$, respectively. The model shows that there is a positive correlation between mechanical resistance and bulk density and also is a negative one between mechanical resistance and volumetric soil water content. The variation of predicted mechanical resistance by MR model against measured data is shown in Figure 2. Considering the coefficient of determination of model $\left(\mathrm{R}^{2}=0.042\right)$, this model could only predict $4 \%$ of variations in the soil mechanical resistance and $96 \%$ of changes in soil mechanical resistance were not explained by the model. This results may be due to the non-linear relationship between phenomenon that is neglected in the regression model. Therefore, non-linear model (MR) was not able to predict soil mechanical resistance properly.

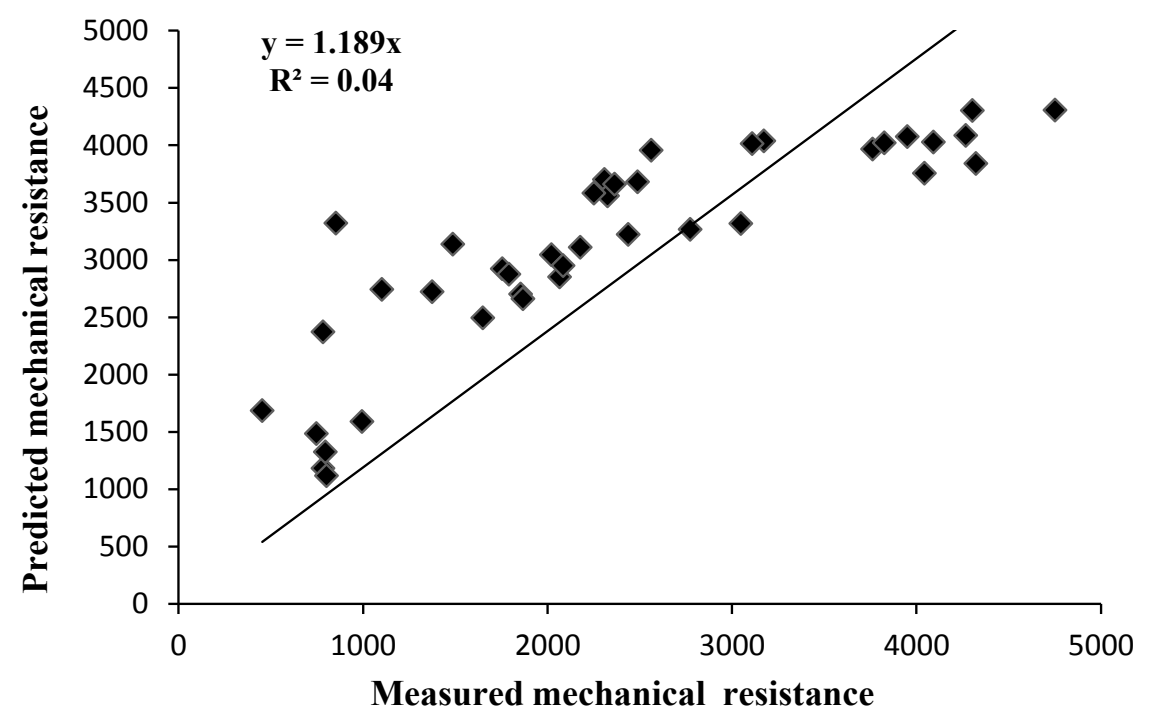

Figure 2. Variation of predicted values of soil mechanical resistance (MPa) against of measured data in MR model.

The validation criteria were presented in Table 2. The best model performance and the most accurate were indicated based on the high value of $\mathrm{R}^{2}$ and VAF and low value of ME, RMSE, and MAPE. Regarding the validation criteria, results showed that ANFIS model had the highest performance to predict soil mechanical resistance. The lowest ME, MAPE and RMSE, and also the highest value of $\mathrm{R}^{2}$ and VAF were obtained for ANFIS model. On the other hand, MR model showed the lowest performance with the highest ME, MAPE, RMSE and the lowest $\mathrm{R}^{2}$ and VAF (Table 2). 
Table 2. Performance indices for different models to predict soil mechanical resistance in the study farm.

\begin{tabular}{cccccc}
\hline Model & ME & RMSE & VAF & MAPE & $\mathrm{R}^{2}$ \\
\hline ANFIS & 1.36 & 299.41 & 93.70 & 16.12 & 0.93 \\
ANN & 30.47 & 450.80 & 85.50 & 25.74 & 0.82 \\
FIS & 330.17 & 739.90 & 69.20 & 44.45 & 0.73 \\
MR & 777.66 & 1002.13 & 71.93 & 59.25 & 0.04 \\
\hline
\end{tabular}

Mean error (ME); root mean square error (RMSE); value account for (VAF); mean absolute percentage error (MAPE); coefficient of determination $\left(\mathrm{R}^{2}\right)$; adaptive neuro-fuzzy inference systems (ANFIS); artificial neural networks (ANNs); fuzzy inference systems (FIS); multiple regression (MR).

Difference between the predicted and real data values of soil mechanical resistance presented in Table 3. For the ratio of predicted to real data values, the accuracy of the model is improved by approaching Mean and $\mathrm{SD}$ to one and zero, respectively. Mean and SD for ANFIS model were 1.06 and 0.24 , respectively but for MR model were 1.58 and 0.67 , respectively (Table
3). ANFIS model had higher accuracy in predicting soil mechanical resistance compared to MR model. Among the studied non-linear models, the non-linear relationship between phenomena was best considered by ANFIS. ANFIS correctly predicted $93 \%$ variation in soil mechanical resistance and could not predict only $7 \%$ of soil mechanical resistance (Figure 3 ).

Table 3. Ratio of predicted to real data values of soil mechanical resistance used in different models (MPa).

\begin{tabular}{ccccc}
\hline Model & Minimum & Maximum & Mean & SD \\
\hline ANFIS & 0.77 & 1.67 & 1.06 & 0.24 \\
ANN & 0.70 & 2.77 & 1.12 & 0.40 \\
FIS & 0.33 & 3.85 & 1.27 & 0.68 \\
MR & 0.89 & 3.90 & 1.58 & 0.67 \\
\hline
\end{tabular}

Standard deviation (SD); adaptive neuro-fuzzy inference systems (ANFIS); artificial neural networks (ANNs); fuzzy inference systems (FIS); multiple regression (MR) 


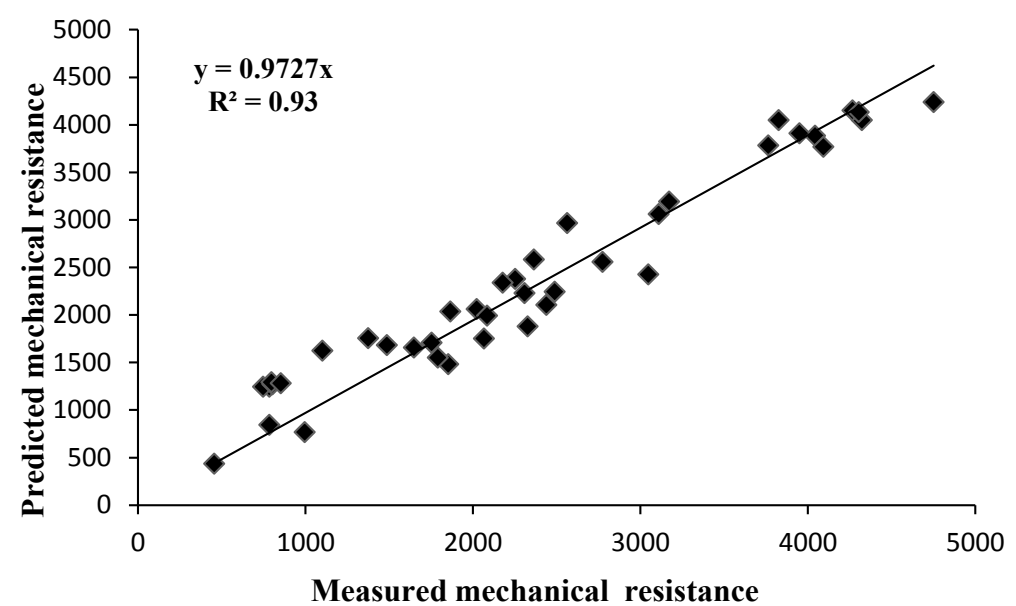

Figure 3. Variation of predicted values of soil mechanical resistance (MPa) against of measured data in ANFIS model.

The highest Mean $=1.27$ and $\mathrm{SD}=0.68$ were with FIS model disregarding regression model. They were 1.12 and 0.40 , respectively for ANN model (Table 3). FIS model expresses $73 \%$ variations in soil mechanical resistance and ignoring $27 \%$
(Figure 4). ANN model expresses $82 \%$ variations in soil mechanical resistance and ignoring 18\% (Figure. 5). Considering this result, ANFIS was the best model for predicting soil mechanical resistance.

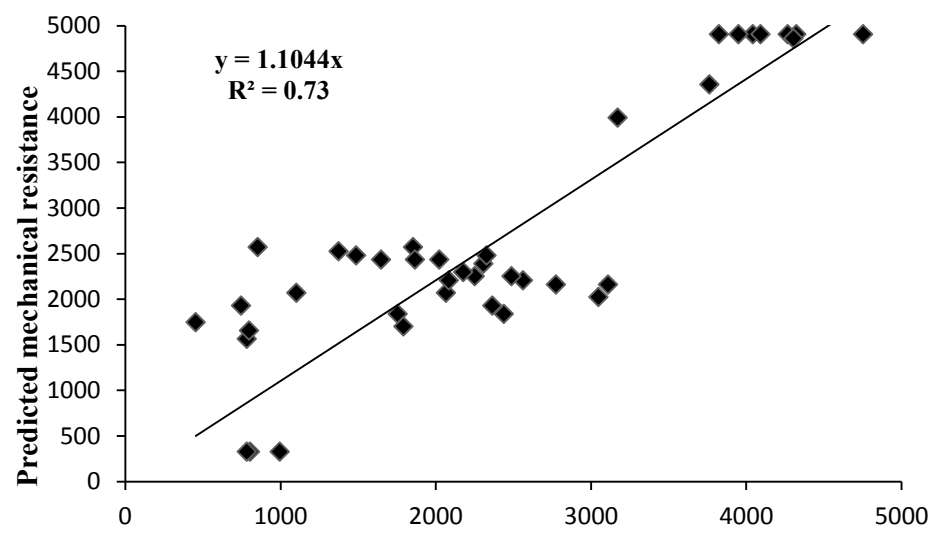

Figure 4. Variation of predicted values of soil mechanical resistance (MPa) against of measured data in FIS model. 


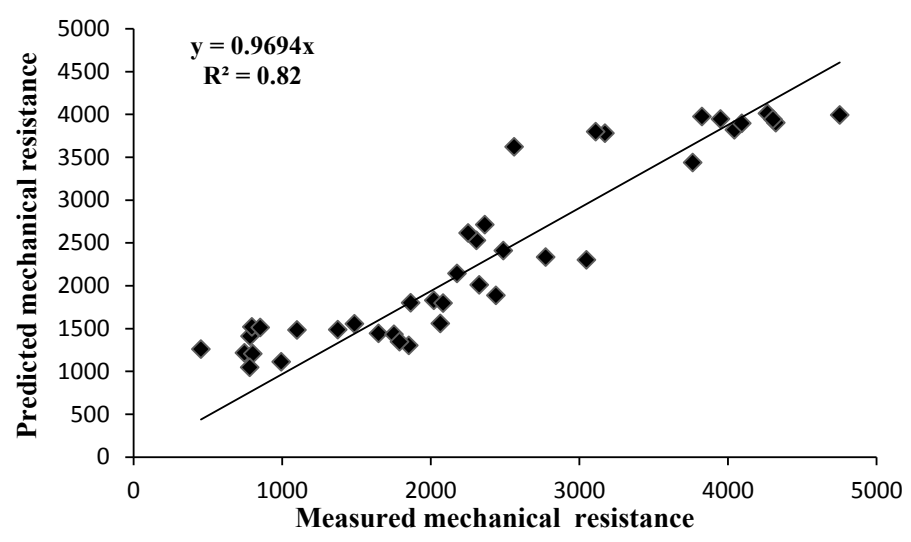

Figure 5. Variation of predicted values of soil mechanical resistance (MPa) against of measured data in ANN model.

\section{Discussion}

Soil mechanical resistance showed higher values in the study site due to high soil specific surface and cohesion between primary particles (Hosseini et al., 2016). Bulk density, pore size distribution, and volumetric soil water content are important soil physical properties in relation to crop production and conserve its value as the first natural filter through their effect on mechanical resistance (Keesstra et al., 2012). Hosseini et al. (2014) reported that tillage practices increased soil pore distribution (macropore and mesopore) which provide more space for root growth and decreased volumetric soil water content. On the other hand, the soil moisture is influenced by the structure of soil that could be described by soil water content, and bulk density, strongly depending both on the matric potential and soil texture (Chaplain et al., 2011). Hosseini et al. (2016) showed that the correlation between soil bulk density and mechanical resistance was positive but there was negative one between soil water content and mechanical resistance. Soil mechanical resistance directly affects seedling emergence and root growth. The other factors such as the parent material (Martínez-Hernández et al., 2017), land management or irrigation (Rodrigo-Comino et al., 2017) decrease soil mechanical resistance in soil depth and increase root density in the rhizosphere, wheat nutrient uptake, and the yield. Therefore, root growth and hence native nutrient uptake (such as potassium) and crop yields maybe increased by increasing the tillage intensity in soils with high specific surface and mechanical resistance. Bengough et al. (2001) reported that an increase in mechanical resistance occurs, when soil water content decreases, due to cohesion within the solid fraction of soil diminishes. Similarly, Hosseini et al. (2016) demonstrated that soil mechanical resistance is affected by soil bulk density and volumetric soil water content under wheat cultivation. Furthermore, Ozpinar and Cay (2006) found that higher soil bulk density resulted in higher resistance to penetration, increasing soil mechanical resistance, and decreasing yield. 
Soil mechanical resistance has been affected by dry bulk density and initial water content in soil samples (Rodrigo-Comino et al., 2017). Moreover, bulk density and soil mechanical resistance influenced on plant growth, which had negative effects on root (Silva et al., 2004).

Contrary to MR model, ANFIS showed the higher performance in the validation criteria. Similar finding was reported by Hosseini et al. (2016) for particle swarm optimization and genetic algorithm in comparison with multiple regression. Therefore, ANFIS model produced more accurate model. Complex and non-linear models probably are able to construct more accurate and powerful relationship between inputs data and target variable (Khaledian et al., 2018). Non-linear relationship such as particle swarm optimization and genetic algorithm models showed promising results for the estimation of soil mechanical resistance in comparison with linear models (Hosseini et al., 2016).

Since the soil mechanical resistance describes the behavior of soils, it is strongly related to bulk density and water content; therefore, it can be influenced by soil compaction. By doing so, land management, such as soil tillage practices would be affected (Hosseini et al., 2016). Hence, predicting these types of soil properties are more difficult to determine, especially when there are restrictions regarding money and time, the findings of this research would be useful.

\section{Conclusions}

The potential benefits of intelligent methods models extend beyond the high computation rates. Higher performances of the intelligent models were sourced from greater degree of robustness and fault tolerance than traditional statistical models, because there are a number of processing neurons, each with primarily local connections. The main objective of this study was to explore the capability of adaptive neuro-fuzzy inference systems (ANFIS), artificial neural networks (ANNs) and fuzzy inference systems (FIS), and multiple regression (MR) in estimation of soil mechanical resistance. The comparisons between four models mentioned above indicate the constructed ANFIS model exhibited higher performance than ANN, FIS and MR models for predicting soil mechanical resistance. Furthermore, time taken by ANFIS model was less than ANN and FIS models in this study. Intelligent methods which used in this research are a good tool for minimizing the uncertainties in the soil engineering projects, expand our knowledge of land management, describes the behavior of soils, and also provided new approaches and methodologies which could minimize the potential inconsistency of correlations.

\section{References}

Adam, E.G. 2003. Data-driven linguistic modeling using relational fuzzy rules. IEEE Transactions on Fuzzy Systems. 11: 121-134.

Bengough, A.G., Campbell, D.J., O'sullivan, M.F. 2001. Penetrometer techniques in relation to soil compaction and root growth. In: Smith, K.A., Mullins, C.E. (Eds.). Soil and Environmental Analysis: Physical Methods. Marcel Decker, New York, USA, pp. 377-404.

Black, C.A. 1965. "Methods of Soil Analysis: Part I Physical and mineralogical properties". American Society of Agronomy, Madison, Wisconsin, USA.

Brasher, B.R., Franzmeier, D.P., Valassis, V., Davidson, S.E. 1966. Use of Saran resin to coat natural soil clods for Bulk-density water retention measurements. Soil Sci. 101: 108.

Cagliari, J., Veronez, M.R., Alves, M.E., 2011. Remaining phosphorus estimated by pedotransfer function. Revista Brasileira de Ciência do Solo 35: 203-212. 
Chang, D.-H., Islam, S., 2000. Estimation of soil physical properties using remote sensing and artificial neural network. Remote Sensing of Environment, 74: 534-544.

Chaplain, V., Défossez, P., Richard, G., Tessier, D., Roger-Estrade, J. 2011. Contrasted effects of notill on bulk density of soil and mechanical resistance. Soil Till. Res. 111: 105-114.

Chapman, H.D. 1965. Cation exchange capacity, P 781-790. In: Black, C.A (ed.). Methods of Soil Analysis. Part 2. American Society of Agronomy, Madison, Wisconsin, USA.

Das, G., Pattnaik, P.K., Padhy, S.K. 2014. Artificial neural network trained by particle swarm optimization for non-linear channel equalization. Expert Systems with Applications, 41: 3491-3496.

Demuth, H., Beale, M. 2001. Neural network toolbox for use with MATLAB. Natick, MA: The Math Works Inc. 840 pp.

Gee, G.W., Bauder, J.W. 1986. Particle-size analysis In: Klute, A. (Ed.), Methods of Soil Analysis, Part 1. Physical and Mineralogical Methods, second ed. Agronomy. 9: 383-411.

Hosseini, M., Movahedi Naeini, S.A.M., Dehghani, A.A., Khaledian, Y. 2016. Estimation of soil mechanical resistance parameter by using particle swarm optimization, genetic algorithm and multiple regression methods. Soil Till. Res. 157: 32-42.

Hosseini, M., Movahedi-Neeni, S., Zeraat Pishe, M. 2014. Effect of porosity, volumetric water content and soil temperature on the water uptake and dry matter yield of plant in different tillage systems. JWSS-Isfahan University of Technology. 18: 133-146.

Jang, J.S.R. 1993. ANFIS: Adaptive network-based fuzzy inference systems. IEEE Transactions on Systems, Man and Cybernetics. 23: 665-685.
Kayadelen, C. 2009. Modeling of the angle of shearing resistance of soils using soft computing systems. Expert Syst. Appl. 36: 11814 - 11826.

Keesstra, S., Geissen, V., Mosse, K., Piiranen, S., Scudiero, E., Leistra, M., van Schaik, L. 2012. Soil as a filter for groundwater quality. Curr. Opin. Environ. Sustain. 4: 507-516.

Khaledian, Y., Brevik, E.C., Pereira, P., Cerdà, A., Fattah, M.A. Tazikeh, H. 2017. Modeling soil cation exchange capacity in multiple countries. Catena.158: 194-200.

Khaledian, Y., Quinton, J.N., Brevik, E.C., Pereira, P., Zeraatpisheh, M. 2018. Developing global pedotransfer functions to estimate available soil phosphorus. Science of the Total Environment. 644:1110-1116.

Liu, J., Goering C.E., Tian L. 2001. A neural network for setting target yields. Transactions of the American Society of Agricultural Engineers. 44: 705-713.

Martínez-Hernández, C., Rodrigo-Comino, J., Romero-Díaz, A., 2017. Impact of lithology and soil properties on abandoned dryland terraces during the early stages of soil erosion by water in southeast Spain. Hydrol. Process. 31: 3095-3109

McLean, E.O. 1982. Soil pH and lime requirement. In: Page, A.L., Miller, R.H., Keeney, D.R. (Eds.), Methods of Soil Analysis, Part 2. Chemical and Microbiological Properties, 2nd ed., Agronomy. 9: 199-224.

Movahedi Naeini, S.A.R., Bagheri, M., Ghorbani, M.H., Riahi, R. 2012. Effects of different irrigation methods on potassium uptake by wheat in soils with high specific surface and truncated electric diffuse double layer. Research Report. Gorgan 
University of Agricultural Sciences and Natural Resources. (In Farsi).

Nasri, B., Fouché, O., Torri, D., 2015. Coupling published pedotransfer functions for the estimation of bulk density and saturated hydraulic conductivity in stony soils. Catena 131: 99-108. doi:10.1016/j. catena.2015.03.018

Negnevitsky, M. 2002. Artificial intelligence: A guide to intelligent systems. England: Addison-Wesley.

Ozpinar, S., Cay, A. 2006. Effect of different tillage systems on the quality and crop productivity of a clay-loam soil in semi-arid north-western Turkey. Soil Tillage Res. 88: 95-106.

Padmini, D., Ilamparuthi, K., Sudheer, K.P. 2008. Ultimate bearing capacity rediction of shallow foundations on cohesionless soils using neuro fuzzy models. Comput.Geotec.35: 33-46.

Pulido, M.M., Gabriels, D., Cornelis, W., Lobo, D. 2015. Comparing aggregate stability tests for soil physical quality indicators. Land Degrad. Dev. 26: 843-852.

Rodrigo-Comino, J., Bogunovic, I., Mohajerani, H., Pereira, P., Cerdà, A., Ruiz-Sinoga, J., Ries, J. 2017. The Impact of Vineyard Abandonment on Soil Properties and Hydrological Processes. Vadose Zone J. doi:10.2136/vzj2017.05.0096

Silva, A.P.d., Imhoff, S., Kay, B. 2004. Plant response to mechanical resistance and air-filled porosity of soils under conventional and no-tillage system. Scientia Agricola. 61: 451-456.
Stegemann, J.A., Buenfeld, N.R. 2002. Prediction of unconfined compressive strength of cement paste with pure metal compound additions. Cement Concrete Res. 32: 903-913.

Yilmaz, I., Kaynar, O. 2011. Multiple regression, ANN (RBF, MLP) and ANFIS models for prediction of swell potential of clayey soils. Expert Sys. Appl. 38: 5958-5966.

Yilmaz, I., Yuksek, A. G. 2009. Prediction of the strength and elasticity modulus of gypsum using multiple regression, ANN, ANFIS models and their comparison. International Journal of Rock Mechanics and Mining Sciences. 46: 803-810.

Zadeh, L.A. 1965. Quantative fuzzy sets. Information and Control, Vol.8, Pp. 338-353.

Zeraatpishe, M., Khormali, F. 2012. Carbon stock and mineral factors controlling soil organic carbon in a climatic gradient, Golestan province. Journal of Soil Science and Plant Nutrition. 12: 637-654.

Zeraatpisheh, M., Ayoubi, S., Jafari, A., Finke. P. 2017. Comparing the efficiency of digital and conventional soil mapping to predict soil types in a semi-arid region in Iran. Geomorphology. 285: 186-204. 